\title{
ETHOS SEM ÉTICA: A PERSPECTIVA CRÍTICA DE T.W.ADORNO E M.HORKHEIMER
}

\author{
Luiz A. Calmon Nabuco Lastória*
}

\begin{abstract}
RESU M 0: 0 propósito deste artigo é o de expor os motivos que levaram T.W. Adorno e M . H orkheimer a não tratar o problema filosófico da moral nas sociedades contemporâneas nos termos de uma teoria ética. Em decorrência disso, a ética assume, na perspectiva desses autores, a dimensão de um impulso que se realiza enquanto crítica racional a uma racional idade supostamente esclarecida.
\end{abstract}

Palavraschave: Ética; Crítica; Esclarecimento; Cultura; M ito.

A palavra ethos significava para os gregos antigos a morada do homem, isto é, a natureza, uma vez processada mediante a atividade humana sob a forma de cultura, ${ }^{1}$ faz com que a regularidade própria aos fenômenos naturais seja transposta para a dimensão dos costumes de uma determinada sociedade. Em lugar da ordenação observável no ciclo natural das coisas (as marés ou as fases da Lua, por exemplo), a cultura promove a sua própria ordenação ao estabelecer normas e regras de conduta que devem ser observadas por cada um de seus membros. Sendo assim, os gregos compreendiam que o homem habita o ethos enquanto a expressão normativa da sua própria natureza. Embora constitua uma criação humana, tal expressão normativa pode ser simplesmente observada, como no caso das ações por hábito, ou refletida a partir de um distanciamento consciente. $\mathrm{N}$ esse caso, adentramos o terreno da ética enquanto discurso racional sobre 0 ethos.

Nos termos do pensamento filosófico de T.W. Adorno e M. $\mathrm{H}$ orkheimer, em que pese as diferenças entre ambos, a impossibilidade da ética no mundo atual remonta, sem dúvida, ao problema da divergência entre ética e razão no transcurso do esclarecimento. Como é sabi-

* Prof. Dr. da Faculdade de Psicologia e membro do Grupo de Estudos e Pesquisa "Teoria Crítica e Educação" do Pós-G rad. em Educação da Unimep. E-mail: lacalmon@unimep.br 
do, Adorno e H orkheimer analisaram o imbricado entrelaçamento entre mito e esclarecimento ao longo da jornada histórica percorrida pela civilização ocidental.

A definição de esclarecimento é tomada de empréstimo de Kant. E, de acordo com Kant, este termo significa a saída do homem de sua menoridade, isto é, o homem já devendo ser capaz de se servir do próprio entendimento sem a direção ou tutela de outrem. Ainda de acordo com Kant, pode-se dizer que uma tal atitude nada mais seria do que 0 entendimento dirigido pela própria razão, tomada em sua utilização prática, de modo a propiciar o comportamento moral autônomo dos homens em sociedade.

Q uanto ao programa do esclarecimento, Adorno e H orkheimer afirmam que a sua principal meta era a dissolução dos mitos, a substituição da imaginação pelo saber. O s autores reportam-se a Francis Bacon, "o pai da filosofia experimental", para ilustrar a tese segundo a qual a superioridade do homem reside em sua capacidade racional de imperar na prática sobre a natureza. $\mathrm{N}$ ão obstante, como veremos adiante, 0 atestado prático fornecido pelas ciências acerca de uma suposta superioridade humana face à natureza apenas atualiza a obstrução da lembrança de que nós próprios somos seres naturais. $\mathrm{E}$, ainda, de que a dominação da natureza externa requer a dominação de nossa natureza interna como contrapartida. Logo, o problema da "dominação" (cujo avesso nos conduz ao problema da "reconciliação") constitui o foco temático da Teoria Crítica.

$\mathrm{D}$ ado que o nosso objetivo neste artigo consiste apenas em tratar o problema da divergência entre ética e razão, problema esse que, como dissemos a pouco, remonta a todo o transcurso histórico que liga o pensamento mítico primitivo ao pensamento esclarecido imperante nas sociedades modernas atuais, exporemos primeiramente a dialética contida no binômio mito-esclarecimento para, a seguir, retomar a questão acerca da incapacidade do chamado pensamento esclarecido de promover a saída dos homens da menoridade. Como veremos, tratase, em última instância, de uma crítica à "racionalidade esclarecida" de um ponto de vista ético. ${ }^{2}$

O s mitos, afirmam os autores, consistiam eles próprios numa forma arcaica de esclarecimento. Eles queriam "(...) relatar, denominar, dizer a origem, mas também expor, fixar, explicar" (Adorno \& H orkheimer, 1985, p. 23). N ão obstante isso, no mundo encantado dos mitos, mundo em que prevalecia uma forma de consciência mágica, podia ser conservada a diferenciação entre as coisas e mantido 0 
princípio da dominação de forma não dissimulada. É nesses termos que os ritos dos xamãs, exemplificam os autores, “(...) dirigiam-se ao vento, à chuva, à serpente lá fora ou ao demônio dentro do doente, não à matéria ou exemplares" (idem, p. 24); vale dizer, não como mais tarde faria a ciência.

Se, por um lado, a atitude mimética - enquanto expressão da consciência mágica - permitia ao xamã assemelhar-se, com suas atitudes, gestos e indumentárias, aos múltiplos espíritos, assegurando assim o reconhecimento da diferenciação no seio da natureza, por outro, essa mesma atitude deixava transparecer, de maneira evidente, o princípio da dominação. 0 horror da natureza manifestado em suas múltiplas formas, "ao ecoar na alma frágil dos selvagens", dirão eles, fazia com que se despojassem da própria identidade para afugentar o medo que os arrebatava. Cabe ressaltar aqui que, para a consciência mágica, a identidade perpétua entre o si-mesmo e o poder invisível da natureza ainda não havia sido proclamada. Q uando da passagem para a ciência moderna, tal identidade é consumada e, por seu intermédio, o princípio da dominação aparecerá invertido. A clara subjugação do homem à natureza se inverterá na subjugação da natureza ao homem. A esse respeito, argumentam os autores ao se referirem a essa relação identitária com o poder: "É só enquanto tal imagem e semelhança que o homem alcança a identidade do eu que não pode se perder na identificação com o outro, mas torna definitivamente posse de si como máscara impenetrável". (Adorno \& Horkheimer, 1985, p. 24)

0 caráter idêntico do eu deve ser mantido a qualquer preço; e a flexibilidade que caracterizava o jogo identitário do xamã para com as diferentes entidades da natureza, bem como a distância entre ele próprio e as máscaras que utilizava, agora cede lugar ao desempenho racional de papéis aos quais o indivíduo deve ajustar-se milimetricamente. 0 homem de ciência acredita dispor da natureza que, sob a forma de meros objetos, sucumbe ao seu arsenal de técnicas. Ele se comporta como um verdadeiro ditador, na medida em que só a conhece por meio de suas manipulações. D aí a afirmação categórica dos autores de que o esclarecimento é totalitário. O u melhor, o totalitarismo é uma possibilidade imanente ao seu desenvolvimento.

0 momento propriamente dialético do binômio mito/esclarecimento, inscrito já na forma de consciência que caracteriza o primitivismo mítico, depreende-se, segundo os autores, desse sentimento de medo com que o "selvagem" experimenta com estranheza o mistério em face 
da natureza da qual ele próprio se diferenciou. É a expressão desse medo originário que se converte em explicação, primeiro mítica e, posteriormente, científica.

N os termos da cosmovisão mítica, a consciência fixa a transcendência do desconhecido em relação ao conhecido, convertendo assim o horror em sacralidade. 0 próprio "conceito", afirmam os autores, enquanto unidade daquilo que está nele subsumido, seria, desde os tempos primordiais, o produto do pensamento dialético. Isso na medida em que, por exemplo, uma árvore é representada como aquilo que ela efetivamente é e, ao mesmo tempo, como morada de um espírito. D esse modo, o seu "nome" abriga uma contradição que leva a linguagem a superar o caráter meramente tautológico pela mediação daquilo que a transcende.

Esse é o motivo que leva os autores à definição do esclarecimento como "radicalização da angústia mítica". M as devemos ter em conta que essa radicalização permanece impotente na medida mesma em que se desenvolve a partir do "grito de terror" como expressão da consciência primitiva. O s deuses, dirão eles, "(...) não podem livrar os homens do medo, pois são as vozes petrificadas do medo que eles trazem como nome" (Adorno \& H orkheimer, 1985, p. 29).

É com o intuito de livrar-se desse medo do desconhecido que, segundo os autores, o esclarecimento teria percorrido todo o trajeto que conduz a civilização ocidental do mito à metafísica, e desta à ratio científica.

M esmo a justiça, uma das categorias centrais para todas as éticas, permaneceria, desde o passado mais remoto, sob o jugo do poder que medeia tanto as relações do homem com a natureza como as relações que se estabelecem entre os próprios homens. Antes e depois de sua absorção pelo D ireito, observam H orkheimer e Adorno, a justiça nunca deixou de exibir as marcas de uma sociedade de opressão. Vimos que 0 xamã esconjurava o perigo por meio da atitude mimética e, para tanto, utilizava-se da igualdade como seu instrumento primordial. Com o desenvolvimento da civilização - em que pese o fato das condições naturais não mais exercerem o seu poder de maneira imediata, mas sim, mediatizada pelo desenvolvimento da consciência moral dos homens - o princípio da igualdade como regulador do castigo e do mérito permaneceu inalterado. A esse respeito, comentam os autores:

Aliás, os homens expiaram essa passagem justamentecom a adoração daquilo a que estavam outrora submetidos como as demais criaturas. Antes, os fetiches estavam sob a lei da igualdade. Agora, a própria igualdade torna-se 
fetiche. A venda sobreos olhos da ustiçanão significa apenas quenão sedeve interferir no direito, mas que ela não nasceu da liberdade. (Adorno \& H orkheimer, 1985, p. 30)

Já na aurora do mundo grego, os mitos deixaram de ser apenas um relato; eles foram incorporados às doutrinas filosóficas. O schamados "princípios primeiros" com os quais as cosmologias naturalistas dos présocráticos procuravam determinar a ordem natural imutável do kosmos, designavam os lugares anteriormente ocupados pelos mitos. Pouco a pouco, “(...) toda a luxuriante plurivocidade dos demônios míticos espiritualizouse na forma pura das entidades ontológicas" (idem, p. 21).

Com a separação entre os deuses e os elementos materiais que aqueles representavam, foi aberto o caminho para que o problema do Ser fosse então resolvido na ordem do logos. $\mathrm{N}$ a metafísica platônica já estaria contido o anseio de toda desmitologização: o equacionamento mítico das I déias com os números nos escritos tardios de Platão nos é apresentado pelos autores como ilustração deste anseio. Adorno e $\mathrm{H}$ orkheimer são também bastante enfáticos ao sublinharem que 0 ideal do esclarecimento residiu na concepção de um sistema do qual se possa deduzir toda e cada uma das coisas, e que a lógica formal foi a "grande escola" que possibilitaria ao pensamento alcançar este ideal. Q ualquer sistema se estrutura por intermédio de suas ordenações lógicas e 0 desenvolvimento de sua coerência racional máxima implica, dialeticamente, na expressão de sua irracionalidade máxima.

Q uando o número tornou-se definitivamente 0 cânon do esclarecimento e o pensamento foi tragado pelos procedimentos da matemática, insurgindo-se contra a pretensão supostamente ainda mítica de verdade dos universais próprios ao legado da metafísica platônicoaristotélica, os autores afirmam que a exigência filosófica clássica de se pensar o próprio pensamento foi abandonada. Em conseqüência disto, a atividade do pensamento reificou-se, transformando-se em mero instrumento adequado à criação dos demais instrumentos. $E$, nesse sentido, o esclarecimento terminou por eliminar os últimos vestígios de sua autoconsciência.

É preciso ressaltar aqui que o que Adorno e $\mathrm{H}$ orkheimer censuram no pensamento esclarecido moderno é, antes de tudo, o fato de que para este tudo pode ser conhecido por meio de um processo que já está decidido de antemão. A esse respeito, comentam eles que:

Q uando no procedimento matemático, o desconhecido setorna a incógnita deuma equação, el e se vê caracterizado por isso mesmo como al go dehá 
muito conhecido, antes mesmo que se introduza qualquer valor. (Adorno \& H orkheimer, 1985, p. 37)

Através da identificação antecipatória, o pensamento esclarecido moderno acredita estar a salvo do retorno ao mito. 0 que esse pensamento não se dá conta, segundo os autores, seria exatamente 0 fato de que, a cada novo passo, se enreda cada vez mais na ordem mítica. E assim, por exemplo, que a mitologia desfecha o processo sem fim do esclarecimento ao fazer com que toda nova teoria termine por sucumbir à crítica arrasadora de ser apenas uma crença, até o ponto em que 0 próprio conceito de verdade seja rechaçado como magia. É assim que o princípio mítico do destino aparece transmutado no princípio da imanência por meio do qual se reenvia à explicação de todo acontecimento pela mera repetição. E assim que na imparcialidade do jargão científico, o substrato concreto da dominação social pode repousar tranqüilamente sobre um conjunto de signos neutros.

Além do mais, a ciência moderna ainda comunga com a magia o fato de que, para ambas, ultrapassar os seus respectivos domínios fechados implica em desvario, no caso da primeira, e sacrilégio, no caso da segunda. A Crítica da Razão Pura aparece aqui como ilustração desse tabu. Conforme as palavras de Adorno e H orkheimer: "A dominação da natureza traça o círculo dentro do qual a C rítica da Razão Pura baniu o pensamento", ou seja, Kant teria combinado a "(...) doutrina da incessante e laboriosa progressão do pensamento ao infinito com a insistência em sua insuficiência e eterna limitação" (idem, p. 38) D essa combinação resulta que, para o pensamento científico, não haveria ser no mundo em que esse pensamento não pudesse penetrar, porém tudo aquilo que pode ser por ele penetrado já não é mais o ser. 0 ser em-si cede lugar aos objetos para o homem.

0 pensamento científico, contudo, terá de assumir o ônus inexorável de promover a dominação universal da natureza às custas de promover igualmente a dominação do sujeito pensante. $D$ aí os autores afirmarem que, em primeira instância: "0 preço que os homens pagam pelo aumento de seu poder é a alienação sobre o que exercem o poder" (idem, p. 24). E, nessa mesma linha de argumentação, proferirem o seu veredicto quanto aos rumos sociais sob a égide do esclarecimento: "A mal dição do progresso irrefreável é a irrefreável regressão" (idem, p. 46).

A "regressão" de que falam os autores significa um processo de "barbarização crescente" levado a cabo pela própria civilização esclarecida; processo esse queéengendrado e conduzido por uma ordem social alicerçada sobre os pilares de uma racionalidade técnica que pressupõe, em última 
análise, que os traços "arcaicos" ainda remanescentes da violência mítica podem ser controlados e/ ou resolvidos pelos dispositivos tecnológicos e pelo exercício do D ireito. Em termos do particular, ou seja, do indivíduo que se concretiza historicamente na atualidade, o termo "regressão" é utilizado para designar o processo por meio do qual as sociedades totalmente administradas operam a liquidação sistemática desse indivíduo. ${ }^{3}$

Se outrora o animismo havia dotado as coisas de alma, agora, com a conversão do esclarecimento em aparato tecnológico, o industrialismo leva à reificação das almas. Portanto, a alienação proveniente da relação de dominação dos homens sobre as coisas naturais possui a sua contraface. 0 preço da dominação, tal como argumentam Adorno e H orkheimer:

(...) não émeramentea alienação doshomens com relação aosobjetos dominados; com a coisificação do espírito, as próprias relaçốes dos homens foram enfeitiçadas, inclusive as relações de cada indivíduo consigo mesmo. Ele se reduz aum ponto nodal das relações efunções convencionais suese esperam dele como algo objetivo. (I dem, p. 40)

0 sistema econômico já provê as próprias mercadorias com aqueles valores que, mais tarde, decidirão sobre o comportamento dos indivíduos. As agências de produção cultural, por seu turno, cumprirão a tarefa de inculcar naqueles toda uma série de condutas tidas como as únicas "normais", "decentes" e "racionais". N estes termos, as reflexões empreendidas pelos autores acerca das sociedades ditas esclarecidas evidenciam que o processo por meio do qual os indivíduos são brutalmente subsumidos pela totalidade do sistema social é tão pouco representativo da "verdadeira qualidade dos homens" quanto o valor econômico é representativo dos objetos de uso.

No âmbito do particular, tudo passa então a ser medido em termos de sucesso ou fracasso e à consciência moral cabe apenas decidir entre o "mal" e o "mal menor" tendo em vista a autoconservação do indivíduo. $\mathrm{N}$ ão lhe é possível julgar a legitimidade das alternativas que se apresentam; esse sentimento de impotência experimentado pela consciência do homem moderno nada mais seria do que o índice subjetivo da heteronomia moral como resultante objetiva última do transcurso percorrido pelo esclarecimento até agora.

Aliás, conforme apontam os autores, o caráter coercitivo da autoconservação que se impõe à consciência moral dos homens já se faz presente na $\mathrm{O}$ disséia de $\mathrm{H}$ omero. D iante da alternativa entre submeterse à natureza ou submetêla a si, o comportamento do herói - Ulisses testemunha a sua capacidade racional de ajustar meios a fins para tornar 
coesa a unidade do "eu" e assim autoconservar-se. Vejamos como Adorno e H orkheimer interpretam o duodécimo canto da 0 disséia, o qual relata o encontro de Ulisses com as sereias:

O caminho da civilização era o da obediência e do trabalho, sobre o qual a satisfação não brilha senão como mera aparência, como beleza destituída de poder. 0 pensamento deU lisses, igualmentehostil à sua própria morteeà sua própriafelicidade, sabedisso. Ele conheceapenas duas possibilidadesdeescapar. U maéaqueeleprescreveaos companheiros. Eletapa os seus ouvidos com cera eobriga-osa remar com todas as forças deseus músculos. (...) A outra possibilidade é a escolhida pelo próprio U lisses, o senhor de terras que faz os outros trabalharem paraele. Eleescuta, masamarrado impotenteao mastro, equanto maior setorna a sedução, tanto maisfortementeelesedeixa atar (...). 0 queele escutanão tem conseqüências para ele, aúnica coisaqueconseguefazer éacenar com a cabeça para que o desatem; masétarde demais, os companheiros- que nada escutam - só sabem do perigo da canção, não de sua beleza- eo deixam no mastro para salvar a eleeasi mesmos. (Adorno \& H orkheimer, 1985, p. 45)

A partir da interpretação que fazem da 0 disséia, os autores também assinalam que o trabalho e a fruição estética já se apresentam separados desde a despedida do mundo pré-histórico. Por esta razão, toda a cultura e, mais particularmente, as obras de arte que são o seu corolário partilham a culpa de uma sociedade edificada sobre as bases do trabal ho comandado.

Conforme suas palavras, as medidas tomadas por U lisses no interior de sua nau quando da passagem pelas sereias, "pressagiam alegoricamente a dialética do esclarecimento". E, nesse sentido, a epopéia já conteria os princípios da "teoria correta", teoria essa que, muito mais tarde, viria possibilitar, por intermédio de seus conceitos e fórmulas, a autonomização da totalidade social face a todos.

$\mathrm{N}$ os termos da análise crítica que Adorno e $\mathrm{H}$ orkheimer fazem do transcurso do esclarecimento até os dias de hoje, evidencia-se que o que faltou a este foi, exatamente, 0 ato de esclarecer-se efetivamente. Em conseqüência, sob os auspícios de um esclarecimento ainda mítico, os homens não alcançaram a maioridade. Pelo contrário, a consciência moral tornou-se ainda mais heterônoma face aos poderosos mecanismos por meio dos quais as sociedades totalmente administradas seqüestram até mesmo os últimos impulsos mais íntimos de cada indivíduo, reduzindo-os a meros consumidores compulsórios.

Portanto, nesse novo ethos cultural remodelado com o auxílio dos diversos instrumentais científicos, cuja conversão no mais recente 
reino de uma implacável heteronomia moral nos é apontada pelos autores, resta apenas aos indivíduos - ao contrário de outrora - mobilizarem as suas energias psíquicas não mais para se deterem diante da força dos costumes e leis sociais, mas para não se deterem entregandose a ela. N outras palavras, a dificuldade para os indivíduos modernos em estado de massificação é a de, justamente, transgredir as normas, e não a de observá-las; pois, como salientou Rouanet (1979), a sua observância é facilitada por todos os automatismos de uma cultura cujo poder de repressão se fez tão abrangente e profundo que deixou de ser percebido como tal.

D esde que o esclarecimento assumiu a forma da ciência moderna, os autores constatam que as doutrinas morais burguesas testemunham a tentativa desesperada de colocar para si um motivo intelectual no lugar da antiga autoridade religiosa já enfraquecida. I sso com o intuito de perpetuarem a moral numa sociedade caracterizada por um irreconciliável conflito de interesses. M esmo Kant, que opôs a moral ao interesse e, dessa forma, subtraiu a razão do campo desse último, terminou, segundo a visão de Adorno eH orkheimer, por limitar a sua crítica esclarecedora, sucumbindo ele mesmo ao princípio mítico da perpetuação inexorável da ordem burguesa.

A solução para o problema moral moderno, tal como afirmou H orkheimer (1990), não está na obediência a mandamentos rigidamente formulados; 0 devaneio idealista da filosofia kantiana, para esse autor, consiste na afirmação ou aposta de que a "boa vontade" seria 0 único bem a partir do qual se poderia avaliar as boas ações independentemente do que essas realmente significam no respectivo período histórico.

Tal como acontece com todas as demais filosofias idealistas criticadas por Adorno e Horkheimer, podemos dizer que também a filosofia moral de Kant revelou-se incapaz de diferenciar a realidade da fantasia; isso porque, como dirá Horkheimer, supõe que "o mundo já deve estar em ordem desde que no espírito tudo esteja em ordem" (H orkheimer, 1990, p. 67). E como conseqüência dessa incapacidade, o pensamento passa a não mais se aperceber dos próprios limites quanto à sua capacidade de intervenção junto à realidade histórica objetiva. A esse respeito, comentam Adorno e H orkheimer: "O burguês que deixasse escapar um lucro pelo motivo kantiano de respeito à mera forma da lei não seria esclarecido, mas supersticioso - um tolo". (Adorno \& H orkheimer, 1985, p. 85) 
Então, o aspecto utópico inerente à filosofia moral kantiana, ou seja, o estabelecimento de uma ordem racional de pessoas atuantes e independentes, cujas decisões se harmonizariam no bem-estar da coletividade, não passaria de uma bela imagem engendrada pelo pensamento ansioso a partir da eternização das categorias próprias ao sistema vigente.

U ma vez que a resolução do conflito entre interesse e moral não pode ser levado a cabo no interior da ordem burguesa, a autoconsciência refletida dessa tensão deve subsistir como teoria crítica da sociedade. Pois bem, afirmamos inicialmente que a crítica de Adorno e H orkheimer ao esclarecimento é empreendida de um ponto de vista ético. Como exposto no início deste artigo, o critério moral próprio ao conceito kantiano de esclarecimento - a saída do homem de sua menoridade foi utilizado pelos autores para avaliar o trajeto histórico percorrido pela civilização ocidental. Para finalizar, buscaremos explicitar alguns contornos do que entendemos por essa dimensão ética que orienta a filosofia desses autores.

Em primeiro lugar, devemos ter presente que, em que pesem os termos por vezes macabros contidos na diagnose traçada por Adorno e $\mathrm{H}$ orkheimer quanto ao estado de coisas que configuram a cultura contemporânea, esses autores, ao contrário do que se costuma pensar, podem ainda ser considerados otimistas. I sso se deve ao fato de que, apesar de tudo o que apontam, ainda vislumbram e depositam esperanças na possibilidade da humanidade alçar-se para fora do círculo mítico em que se vê enredada a civilização ocidental, em seu percurso histórico até os dias de hoje.

Porém, da "diagnose" apresentada não resulta a prescrição de uma práxis suficiente para a erradicação do mal. Apenas uma precondição necessária, ainda que insuficiente, nos é apontada para que a barbárie crescente possa vir a ser contida: retomar nos dias atuais a exigência clássica da filosofia de pensar o próprio pensamento. D essa vez, porém, o pensamento filosófico, tornado cônscio de seu fracasso histórico quanto à promessa de uma vida melhor por meio da realização da razão, deverá prosseguir humildemente em direção à sua meta não alcançada, sem quaisquer pretensões totalizantes, pondo em xeque os próprios mé todos e caminhos tradicionais.

Essa atitude racional de crítica imanente aos fracassos históricos das diferentes expressões, por meio das quais a civilização ocidental tentou levar a cabo a tarefa do esclarecimento, sobretudo no âmbito do pensamento filosófico, aparece formulada por Adorno em sua D ialética 
negativa (1975). N essa obra, a dialética nos é apresentada como expressão de uma forma de consciência ética que impele o pensamento em direção à sua inevitável insuficiência ou, como diz o próprio Adorno (1975), à “(...) su culpabilidad junto a lo que piensa”.

Trata-se então de uma ética do pensamento que, em nome da dor física, bem como de todas as múltiplas formas de sofrimento que se impõem à existência humana, se recusa à supressão idealista da fratura instaurada historicamente entre o particular e o universal, tanto no âmbito rarefeito das conceituações lógicas quanto no plano da justiça que orienta as relações entre os indivíduos e a totalidade social. A esse respeito Adorno comenta que:

Q uien seajustea la disciplina dialécticatendrá, sin duda, quepagar un tributo deamargo sacrifício en lo tocantea la variedad cualitativa dela experiencia. (...) Lo que hay de doloroso en la dialéctica es el dolor, elevado a concepto, por la pobreza de essemundo. (Adorno, 1975, p. 14)

$\mathrm{N}$ esses termos, caberia ao pensamento refletir criticamente acerca da verdade e, também, da falsidade, constitutivas de ambos os pólos em que se acham cindidos um do outro. Visto sob o ângulo do particular, tal reflexão tem como horizonte ético indagar sobre a possibilidade de concretização das "liberdades individuais" mediante o emprego de uma racionalidade não repressiva da totalidade social. Trata-se, então, de não abandonar o que existe de potencialmente crítico e de autenticamente racional no conteúdo do conceito de "indivíduo", objetivando operar um movimento de resistência no instante mesmo de sua liquidação histórica. ${ }^{4}$

Essa tarefa implica a crítica permanente da "identificação absoluta", processo por meio do qual ocorre a sujeição uniformizante das individualidades e, conseqüentemente, a dissolução de toda e qualquer diferença. $\mathrm{N}$ outras palavras, o momento ético contido no pensamento crítico o impulsiona em direção a uma atitude de denúncia, sem trégua, das individualidades realizadas apenas como pseudo-individualidades.

V isto sob o ângulo do universal, uma tal reflexão objetiva desmistificar o caráter fetichista (anti-humano) da totalidade realizada. Diante de uma totalidade falsa e estilhaçada, caberia então ao pensamento dialético prosseguir em sua busca da verdade, compondo figuras dotadas de sentido a partir do seu contato com os fragmentos daquela. Somente uma tal atitude permitiria ainda ao pensamento guardar a esperança de que a totalidade deformada, hoje apreensível apenas por intermédio de seus escombros e vestígios, possa se tornar, algum dia, uma 
totalidade correta e justa. O u para utilizar as palavras do próprio Adorno, o que mais importa ao pensamento é "(...) produzir perspectivas nas quais o mundo analogamente se desloque, se estranhe, revelando suas fissuras e fendas, tal como um dia, indingente e deformado, aparecerá na luz messiânica" (Adorno, 1992, p. 216).

Recebido para publicação em julho de 2001.

\section{N otas}

1. Palavra de origem romana para a qual não há correspondência exata no grego antigo. 0 vocábulo grego paidéa excede, como explica W. Jaeger, a carga semântica específica ao termo latino "cultura". Jaeger, W. Paidéia. São Paulo: M artins Fontes/U N B, 1989.

2. A esse respeito compartilho integralmente da análise realizada por $M$. Tiburi em seu artigo "Adorno e a Impossibilidade da Ética", in: LastórIA, L.A.C.N ., COSTA, B.C.G. da \& PucCI, B. (orgs.), Teoria crítica, ética e educação, Campinas: Autores Associados/U nimep, 2001.

3. A esse respeito, ver o artigo de 0 swaldo Giacoia Jr., "A ética na era da globalização à luz do pensamento de Adorno", in: LASTÓRIA, L.A.C.N., Costa, B.C.G. da \& PucCl, B. (orgs.), Teoria crítica, ética e educação, Campinas: Autores Associados/U nimep, 2001.

4. Ver Giacoia, op. cit.

\section{ETHOS WITHOUT ETHICS: ThE CRITICAL PERSPECTIVE of T.W. Adorno and M. Horkheimer}

ABST RACT: T he purpose of this articleisto present the reasons why T. W. Adorno and M . H orkheimer did not consider the philosophical problem of morality, in contemporary societies, in terms of an ethical theory. T herefore, in these author's views, ethics acquires the dimension of an impulse that becomes effectiveasa rational critiqueto a supposedly enlightened rationality.

Key words: Ethics; Criticism; Elucidation; Culture; M yth.

\section{Referências bibliográficas}

AD O RN O, T.W. Actualidad de la Filosofía. Barcelona: Paidós, 1991. . Dialectica negativa. M adrid: Taurus, 1975. . M inima moralia. São Paulo: Ática, 1992.

ADORNO, T.W. \& HORKHEIMER, M. Dialética do esclarecimento. Rio de Janeiro: Zahar, 1985.

H ORKHEIM ER, M. Teoria Crítica. São Paulo: Perspectiva, 1990. 
JAEGER, W. Paidéa. São Paulo: M artins Fontes/UN B, 1989.

LAST Ó RIA, L.A., COSTA, B.C.G. da \& PUCCI, B. (O rgs.). Teoria crítica, ética e educação. Campinas/Piracicaba: Autores Associados/ Unimep, 2001.

ROU AN ET, S.P. Imaginário e poder. Tese de Doutorado, Universidade de São Paulo (U SP), 1979. 